\title{
Evaluating Transformational Adaptation in Smallholder Farming: Insights from an Evidence Review
}

\author{
Laura Silici, Jerry Knox, Andy Rowe, \\ and Suppiramaniam Nanthikesan
}

\section{Abstract}

The literature on smallholder farming and climate change adaptation (CCA) has predominantly investigated the barriers to and determinants of farmer uptake of adaptation interventions. Although useful, this evidence fails to highlight the changes or persistence of adaptation responses over time. Studies usually adopt a narrow focus on incremental actions that provide limited insights into transformative adaptation pathways and how fundamental shifts in policy can address the root causes of vulnerability across different sectors and dimensions. Drawing on an evidence synthesis commissioned by the International Fund for Agricultural Development's Independent Office of Evaluation, this chapter outlines how lessons from CCA interventions can be transferred via three learning domains that are essential for transformational change:

L. Silici $(\bowtie)$

Independent Consultant, Rome, Italy

J. Knox

Water Science Institute at Cranfield University, Cranfield, UK

e-mail: j.knox@cranfield.ac.uk

A. Rowe

ARCeconomics, Maple Bay, BC, Canada

S. Nanthikesan

Independent Office of Evaluation of the International

Fund for Agricultural Development, Rome, Italy scaling-up (in its multiple forms), knowledge management, and the human-environment nexus. We discuss the implications of our findings on monitoring, evaluation, and learning, highlighting the challenges that evaluators may face in capturing (a) the persistence or durability of transformational pathways, (b) the complexity of "super-wicked" problems, and (c) the relevance of context-dependent dynamics, within a landscape setting. We also address the contribution of evidence reviews to contemporary debates around development policy linked to climate change and agriculture, and the implications and value of such reviews to provide independent scientific rigor and robustness to conventional programmatic evaluations.

\section{Introduction}

Smallholder agriculture represents $75 \%$ of the world's farms (Lowder et al., 2016) and $80 \%$ of the source of food consumed in the developing world (International Fund for Agricultural Development [IFAD], 2020). Yet smallholder farmers constitute more than half of the world's undernourished people; they inhabit some of the most vulnerable and marginal landscapes, and many lack secure land tenure and water rights. These factors further exacerbate their exposure to 
climate change (IFAD, 2020), alongside other sources of vulnerability such as population growth and land fragmentation. Indeed, smallholder agriculture is disproportionately threatened by unpredictable weather patterns, with the impacts of extreme events including floods, droughts, and heat waves having profound implications on both food security and poverty reduction, especially for rural communities dependent on rainfed agriculture (United Nations Environment Programme [UNEP], 2018).

Although extensive information is readily available on the projected agricultural impacts of climate change and on adaptation measures that could help minimize those impacts, assessments that specifically address the vulnerability of smallholder farmers to climate change are very limited (Donatti et al., 2019). Thus, there is a need to better understand how smallholder farmers perceive the risks of climate change, the factors that influence their decisions to adapt, and what adaptation strategies have been practiced and why (Belay et al., 2017).

This chapter draws on the findings of an evidence synthesis commissioned by the IFAD Independent Office of Evaluation (IOE) to inform a thematic evaluation of IFAD's support for smallholder farmers' adaptation to climate change. Evidence reviews aim to provide a transparent and robust assessment of what is known (and not known) in the literature regarding a specific topic, by adopting a systematic methodology to search, screen, and critically appraise a database of scholarly articles, including peerreviewed and grey literature.

Executing the review involved several discrete stages following the well-established guidelines of the Collaboration for Environmental Evidence (CEE; Pullin et al., 2018), ensuring that the outcomes met quality standards with respect to robustness, transparency, and repeatability. The exercise provided a valuable narrative synthesis of the evidence produced over the last $10+$ years on smallholder adaptation to climate change, focusing on how lessons from climate change adaptation (CCA) in smallholder farming could be transferred within three learning domains: (a) scaling-up, (b) knowledge management, and (c) the nexus interactions between the human and ecosystems. We briefly summarize the key findings from the review and discuss their policy and practice implications with respect to monitoring, evaluation, and learning (MEL) under the framework of transformational change, with a focus on the challenges that MEL faces. Specifically, these included addressing (a) the persistence, or durability, of transformational pathways; (b) the complexity of "super-wicked" problems (Levin et al., 2012) that lead to trade-offs across different intervention dimensions and respective goals; and (c) the relevance of context-dependent dynamics, within a landscape setting.

In smallholder farming, transformational adaptation entails adaptive strategies that address the different root causes of vulnerability, internalize aspects of gender, racial, and intergenerational equity (i.e., social and environmental aspects), and enable changes in the wider food system, including solutions at any point in the value chain and diversification into off-farm sectors. Transformative solutions exert influence beyond the boundaries of specific interventions, possibly reaching different sectors (outside agriculture) and dimensions such as gender roles and behavioral changes. More generally, they imply a conceptual shift toward transformative changes beyond incremental adaptive actions. Indeed, adaptation is not a discrete measure, but rather a dynamic and iterative process due to a changing context where the climate is one of many risks (Vermeulen et al., 2015; Wise et al., 2014). The pace of climate variability is also increasing alongside other sources of vulnerability such as population growth and land fragmentation and the emergence of alternative responses (off-farm employment, markets).

Successful implementation and expansion of transformation pathways in smallholder agriculture are underpinned by three mutually interacting factors. First, CCA solutions need to integrate the multiple nexuses between the socioeconomic sphere and the surrounding ecosystem; second, transformation entails scaling-up, in the intermediate or longer term; and third, an effective and usable climate adaptation knowledge base is needed to understand the nexus better in order to promote scaling-up. 


\section{Methodology}

This review was originally conceived as a rapid evidence assessment (REA), an approach designed to deliver a relatively quick synthesis of evidence of existing research on a defined topic. The REA methodology involves defining an explicit research question(s) and following a strict procedure that is not dissimilar to the development of a protocol for conducting a systematic review. An REA is rigorous and has an approach that is tractable and transparent but generally lacks the depth of analysis often associated with a full systematic review. However, REAs are widely used for informing policy decision making. In this study, the overarching question that guided the review was: What interventions have been successful in building smallholders' adaptive capacity and responses to climate change and how have these been effectively transferred as learning outcomes in the three key dimensions of scaling-up, knowledge management, and ecosystem-human interactions? Our review followed the approach developed by CEE (Pullin et al., 2018) of first developing a protocol that guides the execution and describes how the literature searches will be conducted, including the bibliographic sources and search strings, the data extraction methods, quality assessment, and evidence synthesis. The review was constrained by a set of inclusion and exclusion criteria and the research question defined above.

We used a range of bibliographic databases including Scopus, Web of Science, and Science Direct, and web search engines (Google Scholar) and institutional websites for various international development organizations, think tanks, and research institutes. Following trial searches, we selected the search string "smallholder, AND agric* AND climat* AND change, AND adapt*". Collectively, the searches returned 806 sources of evidence. After a thorough screening of the titles and abstracts using a set of inclusion criteria, we selected 132 sources for full-text reading; of these, we then reviewed and synthesized 91. For a detailed explanation of the review methodology with information on the resources used, see Silici et al. (in press).

\section{Key Messages Emerging from the Evidence Synthesis}

\section{Scaling Up Transformative Adaptation Pathways}

Scaling up a process or an initiative may take multiple forms and does not imply only bringing an intervention to scale (to more people, larger areas) or adapting it to similar conditions in different locations (horizontal scaling-up). Scaling up a project can also relate to moving it forward into a more developed, complex phase, possibly including new components, configurations, and stakeholders (diagonal scaling-up). It can also consist of mainstreaming a certain approach into policy, leveraging and catalyzing policy and/or institutional change (vertical scaling-up; Neufeldt et al., 2015). In the latter case, scaling-up processes imply more than just physical or technical dimensions, but also social scaling-up (increasing social inclusiveness) and conceptual scalingup in terms of moving beyond participation to embedding empowerment in the entire development process (Binswanger-Mkhize et al., 2009). With respect to adaptation, social and conceptual dimensions of scaling-up are particularly important to pursue genuinely transformative pathways.

The academic literature on CCA and smallholder farming has predominantly investigated the determinants of (or barriers to) farmer adaptation at a given point in time and for a defined location (Etana et al., 2020). In our review, about one fourth of the publications were quantitative studies addressing barriers and determinants of farmers' adoption of CCA. This evidence base provided valuable insights on the necessary preconditions and the enabling factors (or capacities) that determine smallholders' decisions to act in the face of climate change. Among the former are factors that underpin a farmer's decision to adapt: knowledge regarding climate change, farming and natural resource management, weather information services, and past experience of extreme climate events; collectively, these contribute toward building farmers' consciousness of the need to adapt. However, awareness alone does not trigger change. A series of 
enabling factors of social, economic, environmental, and institutional natures ultimately determine a smallholder's actual capacity and motivation to take action.

Planned adaptation strategies should thus ensure that the underlying determinants of adoption, such as access to knowledge and information, exist alongside other relevant enabling factors, including endowment with productive assets, human capital (education and skills), and institutional support (e.g., farmer groups and collective action; Atsiaya et al., 2019; Bedeke et al., 2019). Profiling different vulnerability categories is also extremely important because smallholders adopt different strategies according to their degree of sensitivity and adaptive capacity beyond their actual exposure to climate change. More well-off farmers, for instance, rely on a stronger economic buffer and usually have stronger connections with formal and informal institutions, which in turn affect their risk perception and adaptive decisions. Policy and institutions must build on this understanding to meet the particular needs and priorities for distinct smallholder groups, with the most notable disparities found in income and gender (Ruijs et al., 2011).

While this branch of research is very useful to understand farmers' decision making and how to support capacity building, it fails to show the changes or persistence of adaptation behavior over time (Etana et al., 2020). Moreover, because of a largely quantitative, linear approach and a predominant interest in mainstreaming technological solutions, these studies have maintained a rather narrow focus on incremental actions and adjustment approaches within the agricultural sector. The outcome is a limited perspective on agriculture-related solutions and a failure to detect innovative adaptation practices that incorporate local wisdom and creativity.

Other studies have adopted a more dynamic, longer term perspective in describing adaptation pathways. Here the concept of a pathway focuses more on an iterative process of decision making, rather than on the outcome, emphasizing the adaptive nature of the decision process itself in the face of high uncertainty and intertemporal complexity, rather than the achievement of a given objective (Wise et al., 2014). Some of the evidence also stresses the need to address the social roots of vulnerability and the necessity for political-economic change to achieve "transformative adaptation" (Bassett \& Fogelman, 2013).

Several key points emerged regarding smallholder farming and transformational adaptation patterns. First, evidence of path dependence corroborates the need to provide financial and institutional support to overcome the behavioral and economic barriers of less endowed households, who could otherwise become locked in vicious cycles of inaction, thereby undermining overall community ability to adapt over time (Etana et al., 2020). In fact, we found that the sustainability of outcomes is better achieved when their distribution is more equitable and inclusive; this implies that all socioeconomic groups and different types of smallholders can respond to risk and vulnerability according to their adaptive capacity. In terms of planning, the review confirmed that no one blueprint or strategy works across all contexts; instead, adaptation should be perceived as a continuum of approaches, ranging from activities that aim to address the different drivers of vulnerability to measures explicitly targeting climate change impacts, including not only farming but also water and soil conservation and off-farm diversification. Planned responses should follow iterative processes, should set out all possible trade-offs (economic, temporal) between alternative strategies, and should be open to assess and envision all possible futures (Vermeulen et al., 2015, 2018). For example, the most viable pathway for some farmers may be to exit agriculture altogether, which itself requires careful management and planning of consequent rural transitions (Stringer et al., 2020).

Although identifying generic solutions is not possible, sustained adaptation and scaling-up do have some recurrent features. These include the need for integrated, multisector interventions; adopting participatory approaches in planning, implementation, and dissemination; and fostering knowledge exchange, peer learning and cocreation of knowledge. Participation and ownership of adaptive solutions are extremely important to ensure equitable scaling-up pro- 
cesses, because inter- and intra-household differences mean individuals react differently to multiple stressors. Institutional aspects are also critically important features in creating successful adaptation pathways. Sustainable adaptation only happens if farmers and their community members have the capacity to organize themselves. Institutional learning, or institutional capacity building, doesn't necessarily entail formalized structures (although linking with formal organizations does confer some advantages), but it is needed to foster adaptation through collective action and social learning. Institutional support, collective action, and participation are also critical in bridging local and scientific knowledge (Arouna \& Akpa, 2019; Stringer et al., 2020; Vermeulen et al., 2018).

\section{Transformative Knowledge Management}

Access to knowledge constitutes one of the most important determinants of smallholders' decisions to respond to risk and is a critical element in building adaptive capacity. Creating the knowledge base that underpins its access and use, however, faces two challenges: Climate solutions have a shelf life, and they are very context specific. Therefore, the way knowledge regarding climate change and variability is produced, transferred, and exchanged is extremely relevant to securing equitable and inclusive scaling-up pathways (Popoola et al., 2020; Roncoli et al., 2010).

Building adaptive capacity does not rely solely on external, scientific knowledge. Knowledge embedded in farmers' experience and tradition is also critically important in raising awareness of climate risks and selecting appropriate responses. In fact, autonomous adaptation is based on farmer perception of climate change and variability. However, autonomous adaptations may be limited in scope and may be not entirely effective over the long run. They can even lead to maladaptation because farmers typically react to the actual threat experienced and do not consider likely future threats (Akinyemi, 2017; Makate, 2019). Knowledge based on local practices also may not be sufficient to prompt more transformative actions that take account of intergenerational equity (Derbile et al., 2016), or to embark into more risky activities (Etana et al., 2020). Bridging local and external knowledge helps broaden farmers' knowledge base to include more forward-looking considerations (Makate, 2019; Shackleton et al., 2015). On the other hand, having a supply of scientific or external information does not imply that it is passed on, understood, and accepted; this depends on how it is communicated and, importantly, if it matches smallholders' needs.

School education, vocational training, and agricultural extension and advisory services (where available) are important enablers of adaptive capacity because farmers with more education and skills are able to understand, trust, and assimilate the information they receive and utilize it to support their needs (Guido et al., 2018; Henriksson et al., 2020). Joining formal groups such as producer organizations, cooperatives, or outgrower programs can allow farmers to gain access to technical skills, market information, weather forecasts, and other relevant information on credit, laws, and policies (Abass et al., 2018). These mechanisms for transferring knowledge help foster adaptive capacity and peer support, but they may not be effective for all smallholders or may even be exclusive of some groups if they have too narrow a technical focus and are conceived as a one-way, top-down transfer. The actual way in which knowledge is transferred to smallholders and how it then interacts with local knowledge is critically important.

Knowledge can be produced and circulated via more participatory ways. Partnerships and social learning (deep understanding and assimilation of concepts through social interaction) were identified in the literature as promising ways to link science, policy, and practice to tackle multiple and related challenges of agricultural development, food security, and climate change adaptation. The evidence showed that beyond empowering specific groups, inclusive learning processes (such as pro-poor research and gender transformative approaches) accelerate and improve development outcomes for everyone (Shaw \& Kristjanson, 2014). Both formal groups and informal collective action, such as self-help 
neighborhood networks, work-sharing groups, and other community-based organizations, can foster synergies for social learning and capacity building. However, registered community-based organizations seem to be more significantly associated with adaptation (Khanal et al., 2019). Synergies between informal and formal structures also result in more effective organizations because they promote institutional learning, drive innovation and knowledge from external sources, and enlarge participation to more heterogeneous groups (Hulke \& Revilla Diez, 2020).

Learning platforms based on participatory action research (PAR) that bring together different actors have been shown to be particularly effective in supporting adaptation strategies. They rely on social learning and collective action and help external actors (researchers, policymakers, and development institutions) assess community-based perspectives and existing adaptation options, using these as a starting point for further action (Asociacion Andes, 2016; Wekesa et al., 2017). This type of research can also help in situations where climate change is not the only externality but one of multiple sources of vulnerability, thereby providing a deeper understanding of the contextual barriers to adaptation. By fostering inclusion, social learning eases access to knowledge by women and people in other vulnerable categories who are not always targeted by institutional information sources in agriculture (Kerr et al., 2018; Mapfumo et al., 2013).

Several examples in the literature reported successful aspects of social learning through collaborative approaches that were broadly formalized into learning platforms or alliances. Farmer field schools (FFS) may also be considered as a relevant learning platform that integrates adaptation at different levels and scales, albeit the degree of participation in needs assessment and design of training modules is not as high as in PAR (Chandra et al., 2017; de Sousa et al., 2018). For learning platforms to be effective in promoting social learning and collective action in adaptation, strong facilitation is needed that minimizes power imbalances and builds trust among different stakeholders. One or more formal institutions should act as a broker to liaise between different interest groups and to mediate and coordinate partnerships. External actors may also have a role in creating or enhancing the demand for knowledge, thereby helping to overcome the limitations associated with relying only on local knowledge.

Researchers taking part in learning platform have to mind-shift into a learner role and need a deep understanding of local cultural norms and institutions to ensure inclusion of all views (e.g., to separate women and men in consultations, and to look beyond existing community groups that may include only stronger members). Time is also needed to build trust and a safe and comfortable interface environment through appropriate communication before the inception phase. Finally, economic incentives may also be needed to include marginalized categories who may not have time to engage in consultation activities (Shaw \& Kristjanson, 2014). To work well, PAR and learning platforms also need a supportive institutional environment, reflected in economic support but also in an adequate policy and legislative framework (Chandra et al., 2017).

\section{Ecosystem-Based Adaptation and Landscape Approaches in Smallholder Farming}

Individual smallholder farms are typically small, but their collective share of contributions to the ecosystem burden cannot be ignored. Ecosystem goods and services are the backbone of farmers' agricultural economy. Common natural pool resources such as forests and wetlands provide complementary sources of livelihoods and, more generally, a healthy and productive landscape encourages households to remain in rural areas, slowing down outward migration from the countryside while increasing income opportunities and sustaining local adaptation (Arouna \& Akpa, 2019; Food and Agriculture Organization of the United Nations, 2014). The interactions between farming and the environment also have negative connotations, with farmers often exposed to natural disasters and weather extremes. On the other hand, even if smallholder agriculture does not contribute to water and air pollution as much as large-scale intensive farming does, anthropo- 
genic activities such as grazing, encroachment, and deforestation may severely undermine the natural resource base and ultimately smallholders' livelihoods. When taken collectively, these small units can still pose a heavy burden on the ecosystem; at the same time, just due to their large number and small scale, they can play an innovative role in forging beneficial ways of interaction between agriculture and the environment.

Despite these important connections, the review identified relatively few studies that focused explicitly on the nexus between humans and their surrounding ecosystems, or that used an environmental lens to critique adaptation within smallholder agriculture. These findings may well be influenced by the inclusion criteria defined in the review, but the fragmented evidence on this topic nevertheless reflects a reality where policy planning in agriculture, environment, and climate change still happen in silos, with limited exchanges between disciplines (El Chami et al., 2020). This is a key concern and should be recognized as a strategic development priority and considered explicitly in program evaluations.

Other areas of intervention can support stronger nexus integration between human and ecological systems in adaptation planning, implementation, and assessment. First, several studies stressed the need for a reframing of smallholder farming and agriculture more generally, and for an integrated system alongside natural resource management, energy, and climate change. Agricultural sustainability is a threedimensional model that requires overcoming disciplinary boundaries. A transdisciplinary approach, which represents a step forward for interdisciplinarity with full integration of different disciplines, is much needed (El Chami et al., 2020). Such an approach should be pursued through policies that promote circular models of the economy and cyclical, rather than linear, growth-oriented systems. The economic analysis undertaken to inform such policies should reflect this complexity. That is, analysts should be able to value the costs and benefits beyond the conventional measures of productivity and efficiency to include, for instance, the economic value of ecosystem goods and services and GHG mitigation, and thereby identify suboptimal equilibria where the different economic, social, and environmental objectives are consistently achieved (Reid et al., 2013).

Beyond stressing the importance of assessing adaptation responses through an integrated, cross-sectoral approach, the evidence review also highlighted the relevance of local and landscape dimensions. The ecological aspects of adaptation responses and land use changes are closely linked to local socioeconomic conditions: different locations, albeit close to each other, may take different adaptation paths and these should be contextualized within the agro-ecological landscapes in which they reside (López et al. 2020; Marquardt et al., 2020; Newsham \& Thomas, 2009). Thus, a holistic approach to adaptation in smallholder agriculture should cut across not only sectors but also across multiple levels of intervention, from the household level through the community, right up to the landscape level.

In this context, ecosystem-based adaptation (EBA) has been proposed as an effective tool to achieve such an integrated vision (Abdelmagied \& Mpheshea, 2020; El Chami et al., 2020; Vignola et al., 2015). Agro-forestry, for instance, has shown high potential to enhance smallholders' adaptive capacity (Lasco et al., 2014; Partey et al., 2018; Quandt, 2020). Other studies have highlighted that smallholders were aware of the links between the ecosystem and their economic activities, and many already use practices that could be classified as EBA (Chain-Guadarrama et al., 2019; Shah et al., 2019). However, the evidence also calls for greater involvement of researchers and policymakers to address some key challenges. These include, for example, integrating the farmers' local knowledge with results from scientific research and extension services to help manage and minimize the trade-offs at farm and landscape levels, such as competitive interactions between trees and crops, or pest infestations that can result from ecosystem stabilization (Lasco et al., 2014; Quandt, 2020). Scientific and economic research could also help quantify the economic returns from ecosystem goods and services, such as pest and disease control or the role 
of trees as buffer strips. Economic incentives based on these analyses are much needed because EBA approaches constitute long-term strategies with generally low returns (and hence incentives) in the short term.

Our review also showed that institutional support to social networks and collective action was very important in smallholders' pursuing adaptation pathways that assimilate the nexus between human and ecological systems. Being part of a network helps farmers to coordinate collective action around common pool resources. Strong social networks, coupled with the presence of environmental champions, can help facilitate the spread of knowledge-intensive practices for adaptation, such as agro-ecology, and lead to higher environmental sustainability in smallholder farming (NyantakyiFrimpong et al., 2019; SaintVille et al., 2016).

Some authors advocated for combining EBA and community-based adaptation and mainstreaming them into large-scale planning. According to Reid (2016, p. 5) "good EBA should (but does not always) have a strong community focus." The participatory dimension of EBA is easily explained by the fact that many (although not all) natural resource and environmental practices transcend administrative boundaries and go beyond field limits, requiring collective agreement and action. Indeed "good" community-based adaptation often considers ecosystems and ecosystem services to a strong degree. Local adaptation activities in the field tend to combine the two approaches and compensate for the shortcomings of top-down initiatives based on hard infrastructure (Reid, 2016). However, to achieve fruitful integration of these two approaches at scale, an important component is addressing the policy context to assess whether governance is actually inclusive for all community members, whether there is devolution of rights and responsibilities to local institutions, and how this works in practice. Incentives are needed both for individuals and community groups. These could be distributed via external funding for public projects and initiatives, as financing tools such as offering microcredit or revolving funds, or as payments for ecosystem services (PES) and direct compensation (Reid, 2016).

\section{Policy Shortcomings}

Policymakers play a key role in supporting smallholders' adaptation to climate change. Policies at national and international levels define and influence adaptation pathways, first and foremost by setting the vision that underlies the legal and the institutional frameworks. High-level, public intervention is needed to ensure that autonomous adaptations (that may be guided by short-term perspectives) and planned adaptations (more forward looking to intergenerational sustainability) work consistently toward virtuous patterns of transformative adaptation. Evidence showed that path dependence in farmers' choices to uptake adaptation calls for higher level coordination and investments across three intervention scaleshousehold, community, and landscape. Institutional and financial support is necessary to preserve local adaptation efforts (e.g., through infrastructure) and to secure an enabling policy and legal environment (e.g., land tenure, access rights to natural resources). External institutions such as government and development actors should also provide economic incentives to ensure that environmental considerations are fully integrated into human responses (such as compensation for investments in agroforestry that don't deliver immediate returns) and, more generally, to reconcile the unavoidable trade-offs between competing objectives in the economic, social, and environmental domains.

The narrative that emerged from the review highlights that policies would need to undergo some fundamental shifts to support adaptation pathways that are genuinely inclusive and sustainable. First, adaptation strategies should address the root causes of vulnerability, which in the farming sector may lie in complex situations where climate change is just one of multiple stressors. This implies pursuing transformative strategies that have a holistic, intersectoral approach, keeping open all the options for response (including, for example, exiting agriculture). Within the agricultural sector, this means welcoming system-oriented solutions that go beyond technological interventions at plot and farm level; in fact, such interventions may prove to be only coping strategies and, if not well targeted, might also generate 
or exacerbate inequalities at the expense of poorer, less knowledgeable, or less connected farmers. Indeed, addressing the root causes of vulnerability also requires assessing and, if necessary, rebalancing power relationships and politics of knowledge at the community level to avoid asymmetries in access to knowledge and information, the exclusion of most vulnerable groups, and elite capture of benefits. Finally, policy plays a fundamental role in reorienting science and research toward more participative, multistakeholder, and transdisciplinary approaches, according to the principles discussed above.

However, the evidence presents a largely empirical approach and we often perceived a seeming disconnection between policy, research, and practice. Although extensive empirical literature exists on the impacts of climate change, policymakers do not systematically use the evidence available (Khan \& Akhtar, 2015). A further problem is that while many studies identify barriers to adaptation in farming, the appreciation of their interactions and impacts remains scarce. At the policy level, perceptions of climate change mainly as an environmental issue rather than a broad development issue results in it often being sidelined, constituting a barrier to planning and implementing effective actions. Other political barriers include a shortfall of funding and insufficient coordination (Shackleton et al., 2015). Poor interaction between different disciplines, both in research and in policy, was identified as a further gap. Although recognition is growing that smallholder farming and the surrounding ecosystem are tightly coupled, most climate change interventions in agriculture have still focused on farm-related technological solutions. A technocentric approach risks neglecting environmental and natural resource dimensions because it does not solve problems from a holistic perspective. It also risks exacerbating income and gender inequalities because access to assets and skills is often gender biased and generally interdicted to the most vulnerable.

Pursuing the idea of adaptive development may help overcome some of these limitations and promote a truly transdisciplinary approach where reducing societal inequality and injustice is a pre- requisite for adaptation that works for everyone (Lemos et al., 2013). However, several fundamental barriers need to be overcome. At national levels and in international forums, an original disconnection exists between farmers, technical experts, and policymakers and coordination remains limited. True participation by smallholders in the decision-making process is scarce, with "participation" often reduced to consultation, and the devolution of power is weak. As a result, policies often do not reflect smallholders' real needs and preferences, which risks reinforcing vicious circles of power imbalance and inequitable adaptation outcomes (Hameso, 2017; Nigussie et al., 2018; Sova et al., 2015; Taylor, 2018).

Further challenges lie in the difficulties of mainstreaming successful local adaptation solutions into large-scale planning; because climate impacts are often locally specific, large-scale initiatives to support smallholder farmers must consider local priorities and integrate lessons from successful autonomous adaptation efforts. Scaling up climate adaptation into large-scale agricultural initiatives requires not only integration of lessons from community-based adaptation (i.e., learning local priorities, capacities, and lessons), but also the building of inclusive governance. Mainstreaming community-based adaptation, in particular, is more than scaling-up of specific adaptation practices or knowledge; it is about mainstreaming institutional and organizational approaches that allow this knowledge to be generated (Wright et al., 2014). According to this vision, securing impact at scale in practice involves providing the lawful circumstances to embed local institutions into broader governance frameworks, to legally devolve rights and responsibilities to local groups and communities (especially with regard to natural resource management) and to reform land tenure and rights to access natural resources as required (Reid, 2016).

One major opportunity to bring social learning on adaptation to the national level is via existing extension and advisory services, but in many lower-middle income countries, extension services are limited and often biased to target relatively wealthier households (Wright et al., 2014). 
Another way to support effective knowledge sharing is through stakeholder platforms. Stakeholder consultations in policy and in research help consider the multiple and sometimes competing objectives among different sectors and interest groups, and the resulting trade-offs in the distribution of benefits and costs (Abegunde et al., 2019). Stakeholder-centered methods are increasingly used alongside other trade-off analysis methods oriented to better management, that is, with the aim to improve the relative situation for different groups, acknowledging that eliminating trade-offs and generating win-win solutions for all is not possible (Gusenbauer \& Franks, 2019).

\section{Implications for Monitoring, Evaluation, and Learning}

Evidence assessment and continuous learning are critical to inform policy makers about what works for whom. In the context of the three learning outcomes of relevance to this study, monitoring, evaluation, and learning (MEL) should be able to capture the success of both autonomous and planned adaptation strategies in pursuing transformative pathways in smallholder farming. The outputs from the review highlighted a number of challenges for MEL in attaining this goal, and showed opportunities for innovation and crosslearning from different disciplines and methodological approaches.

One challenge lies in the need to evaluate the durability and the persistence over time of nonlinear development processes. The evidence in the literature on scaling-up and knowledge management showed that social equity remains a key factor of transformational patterns; on the other hand, the reiteration of inequitable starting conditions coupled with scarce opportunities for building adaptive capacity causes path dependence in farmer decision making, leading to technology lock-in situations and possibly maladaptation. Enabling countries and organizations to better assess and evaluate transformative adaptation thus requires an inclusive approach built on effective knowledge sharing and atten- tion to the behavioral and institutional changes that address the needs of the most vulnerable (Anderson, 2011). Without understanding how vulnerability to climate change is produced and distributed, planned adaptations may inadvertently promote injustice and deepen inequality. Inequality of outcomes may be channeled through wealth, gender, and local relationships that influence dynamics of power, knowledge flow, and uptake of certain technologies. Therefore, at a higher level, evaluation should seek to consider not only the outcomes of adaptation but also the processes behind them, to understand whose preferences and priorities have guided the decisions and the actions that have been implemented. At the operational level, a fundamental challenge to monitoring is that adaptive strategies also take time to implement and deliver impacts that can be monitored; key milestones are therefore needed to track actual changes over time.

Another related challenge for those engaged in evaluation is that complex, iterative, adaptive processes may often cut across different sectors beyond agriculture. MEL should be able to assess outcomes cutting across sectors (transdisciplinary) and take into account these relationships-and the trade-offs - across different intervention domains with different and sometimes competing goals (e.g., food security and conservation). The evidence showed that failing to fully acknowledge the interactions between the human and environmental systems, and continuing to treat agriculture separately from the environment, may undermine a full understanding of adaptation solutions both in agriculture and beyond. The ecological aspects of adaptation responses in agriculture, and more generally in land use changes, are closely linked to the social and economic dimensions of migration, labor, and shifting production patterns. These interlinkages are highly dependent on context and framed within the scope of landscapes that do not necessarily overlap with administrative boundaries and/or productive areas. These considerations call for MEL in agriculture to redefine both its focus (beyond the farming sector) and its scope (across traditional boundaries): Evaluators 
should go beyond the project or program scale and use the community and landscape dimensions as the scope for evaluating contextdependent dynamics. At a higher level, a conceptual shift is needed in what is conventionally valued as productive and efficient in agriculture in order to embed considerations of inter- and intragenerational equity (including ecological sustainability) into the assessment of adaptation outcomes.

Not only is a conceptual shift required, but changes and improvements in methodology are also necessary to assess and evaluate adaptation to climate change in agriculture. One operational challenge lies in the fact that adaptive strategies take time to bear outcomes that can be monitored, so evaluators need to identify and track key milestones toward the actual change. Another issue is that current $\mathrm{M} \& \mathrm{E}$ approaches mostly rely on purely quantitative methods, which are not suited to understanding complex processes and interactions or to including more nuanced perspectives on equity and vulnerability. More expertise is needed on evaluation applied to adaptation and on the combined application of quantitative and qualitative approaches (Anderson, 2011). Evaluators should also use innovative approaches in economics to value ecosystem goods and services; to assess trade-offs more systematically across different sectoral, spatial, and time scales; and to better evaluate social costs and benefits in the calculation of PES and other economic incentives for farmers.

Finally, improvements in governance are inherently difficult to assess, and so too is understanding how benefits are distributed among different groups. Indeed, even agreeing on a definition of successful adaptation may be difficult because different interest groups will evaluate the same outcome differently. Although using participatory approaches and mutual learning is critical to overcome these issues, they create difficulty in producing impartial and definitive assessments (Anderson, 2011). In this context, stakeholder platforms provide a promising tool (alongside other analytical methods) to encourage mutual learning, communication, and gover- nance in adaptation. These platforms also may be useful to inform the development of innovative MEL approaches.

\section{Future Role of Evidence Reviews in Programmatic Evaluation}

Beyond providing valuable insights and new evidence on climate change adaptation in smallholder agriculture, this type of review can also feed into broader discussions on how evidence from a range of sources (including systematic and rapid evidence reviews) can be usefully integrated into thematic evaluations and what added value such syntheses can provide for MEL. The value to MEL can be explained in relation to a pyramid of evidence (Fig. 1) where the base represents the degree of uncertainty and the different levels represent increasing consensus for different types of enquiry. In evaluation exercises, one task is usually to gather all available data and information from a range of sources (including project design and progress reports, and semistructured interviews with key informants and stakeholders) to corroborate and/or triangulate expert opinion. The rationale is to realize the potential of the data gathered to inform the evaluation while minimizing any bias and uncertainty in the final judgement. Although evaluation panels can access different target audiences, the information they acquire is subject to uncertainty. This could include, for example, the timing and scale of enquiry; the resources available to conduct in-depth, in-country technical missions; access to independent key informants; the relevance of monitoring data; and personal subjectivity. Conclusions also tend to rely on expert judgement that depends on many factors including the evaluation experience and discipline expertise of individual team members.

Traditional literature reviews also can provide valuable insights for evaluation exercises but are contingent on the sources available (and used), the skills of the researcher in framing and executing the searches, the scope of the review, and the method of analysis with inferences based on only a sample of the available evidence. In contrast, 


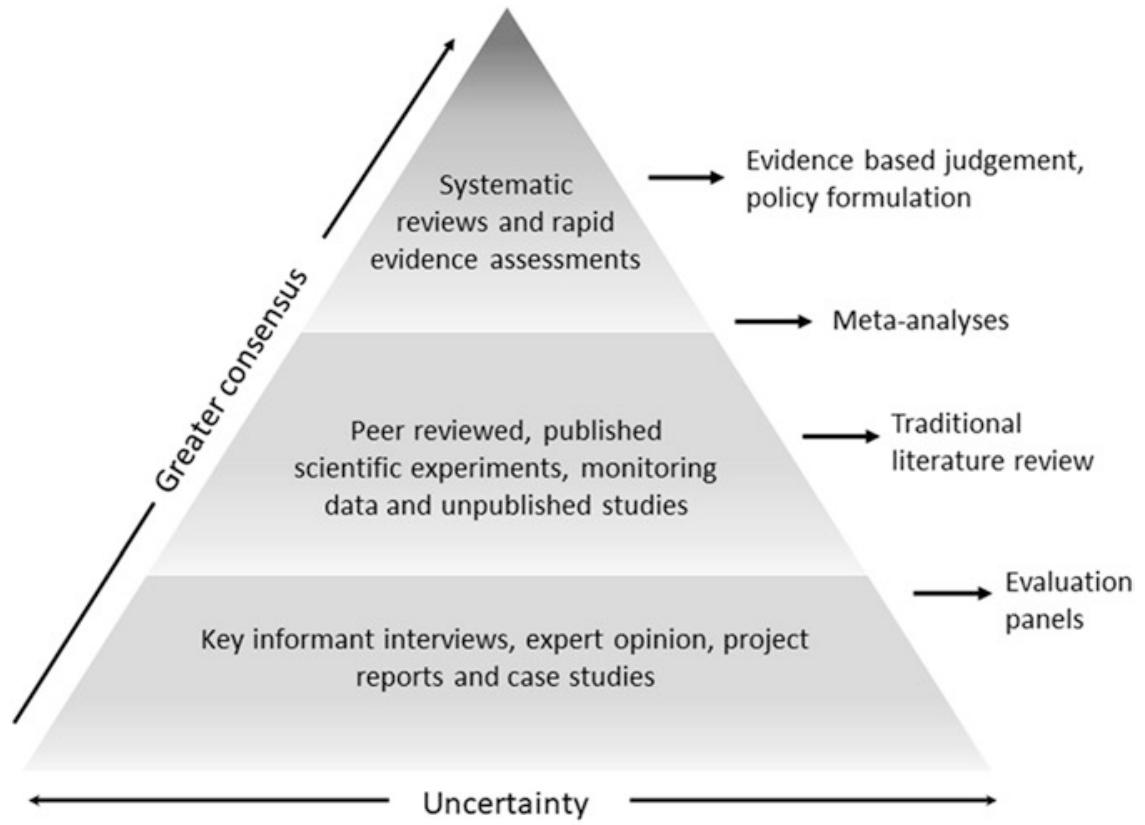

Fig. 1 Pyramid of evidence to support project and program evaluation

systematic reviews are often considered to be at the top of the pyramid of evidence hierarchy, providing the highest degree of consensus and lowest amount of uncertainty, given their highly structured and systemic methodology. Rapid evidence assessments (REAs) are consistent with many of the systematic review principles and popular for informing decision making and policy formulation.

This synthesis of evidence was based on the structured methodology for an REA, although it ultimately presented a much deeper and wider ranging level of analysis more usually associated with a systematic review. This narrative synthesis required a hybrid approach articulated across three related yet distinct learning domains, with each characterized by a high degree of complexity. We chose the REA framework because it can be designed and executed in a relatively short time span (1-3 months) depending on the scope of the research question and available literature, compared to 3-6 months for a systematic review. As such, it is more appropriate for informing programmatic evaluations where a relatively quick synthesis of evidence is required. An REA can also provide a deep understanding of the volume and characteristics of evidence that is available on a certain topic and make it more accessible for further scrutiny. Hence, REAs can facilitate answering targeted, research-based evaluation questions by maximizing use of the existing evidence base, while also providing a clear picture of the adequacy of that evidence (Collins et al., 2015).

Evidence reviews can also help evaluators contextualize projects and programs within a broader picture for use in comparing their results with findings drawn from international evidence. Thus, they can help evaluators understand how conceptual issues are addressed across different disciplines and timeframes, with support from a wider pool of case study material. In some instances (for example, when exploring nexus issues between the human system and ecosystem in the agricultural literature), REAs can help identify existing gaps in knowledge and emerging trends in research, policy, and practice to inform how these gaps and trends might then affect intervention outcomes. Finally, evidence reviews can also help connect research communities with practitioners by providing valuable and informed access to the 
peer-reviewed scientific literature that is either overlooked or not known to exist within the project and program evaluation community.

Acknowledgements This research was funded by the International Fund for Agricultural Development (IFAD) as part of a broader thematic evaluation of their global development program on smallholder adaptation to climate change. The authors acknowledge colleagues from the thematic evaluation team who provided valuable critique and feedback on this review, including Nurul Alam, James Gasana, Margarita Borzelli Gonzalez, Christian Hergarten, Prashanth Kotturi, Susanne Leloup, Carsten Schwensen, and Horst Weyerhaeuser. The opinions expressed in this chapter are those of the authors and do not constitute a formal view from IFAD.

\section{References}

Abass, R., Mensah, A., \& Fosu-Mensah, B. (2018). The role of formal and informal institutions in smallholder agricultural adaptation: The case of Lawra and Nandom Districts, Ghana. West African Journal of Applied Ecology, 26, 56-72. https://www.ajol.info/ index.php/wajae/article/view/182466

Abdelmagied, M., \& Mpheshea, M. (2020). Ecosystembased adaptation in the agriculture sector - A naturebased solution $(\mathrm{NbS})$ for building the resilience of the food and agriculture sector to climate change. Food and Agriculture Organization of the United Nations. http://www.fao.org/3/cb0651en/CB0651EN.pdf

Abegunde, V. O., Sibanda, M., \& Obi, A. (2019). The dynamics of climate change adaptation in sub-Saharan Africa: A review of climate-smart agriculture among small-scale farmers. Climate, 7(11), 132. https://doi. org/10.3390/cli7110132

Akinyemi, F. O. (2017). Climate change and variability in semiarid Palapye, Eastern Botswana: An assessment from smallholder farmers' perspective. Weather, Climate, and Society, 9(3), 349-365. https://doi. org/10.1175/WCAS-D-16-0040.1

Anderson, S. (2011). Assessing the effectiveness of climate adaptation. International Institute for Environment and Development.

Arouna, A., \& Akpa, A. K. (2019). Water management technology for adaptation to climate change in rice production: Evidence of smart-valley approach in West Africa. In A. Sarkar, S. R. Sensarma, \& G. W. vanLoon (Eds.), Sustainable solutions for food security (pp. 211-227). Springer International.

Asociacion Andes. (2016). Resilient farming systems in times of uncertainty: Biocultural innovations in the Potato Park, Peru. International Institute for Environment and Development. https://pubs.iied. org/14663IIED
Atsiaya, G. O., Ayuya, O. I., Nakhone, L. W., \& Lagat, J. K. $(2019,7)$. Drivers and responses to climate variability by agro-pastoralists in Kenya: The case of Laikipia County. SN Applied Sciences, 1, 827. https:// doi.org/10.1007/s42452-019-0849-x

Bassett, T. J., \& Fogelman, C. (2013). Déjà vu or something new? The adaptation concept in the climate change literature. Geoforum, 48, 42-53. https://doi. org/10.1016/j.geoforum.2013.04.010

Bedeke, S., Vanhove, W., Gezahegn, M., Natarajan, K., \& Damme, P. V. (2019). Adoption of climate change adaptation strategies by maize-dependent smallholders in Ethiopia. NJAS - Wageningen Journal of Life Sciences, 88, 96-104. https://doi.org/10.1016/j. njas.2018.09.001

Belay, A., Recha, J. W., Woldeamanuel, T., \& Morton, J. F. (2017). Smallholder farmers' adaptation to climate change and determinants of their adaptation decisions in the Central Rift Valley of Ethiopia. Agriculture and Food Security, 6, 24. https://doi.org/10.1186/ s40066-017-0100-1

Binswanger-Mkhize, H. P., de Regt, J. P., \& Spector, S. (2009). Scaling up local and community driven development: A real world guide to its theory and practice. World Bank. https://openknowledge.worldbank.org/ handle/10986/28252

Chain-Guadarrama, A., Martínez-Rodríguez, R. M., Cárdenas, J. M., Mendoza, S. V., \& Harvey, C. A. (2019). Uso de prácticas de Adaptación basada en Ecosistemas por pequeños cafetaleros en Centroamérica. Agronomía Mesoamericana, 30(1), 1-18. https://doi.org/10.15517/am.v30i1.32615

Chandra, A., Dargusch, P., McNamara, K. E., Caspe, A. M., \& Dalabajan, D. (2017). A study of climatesmart farming practices and climate-resiliency field schools in Mindanao, the Philippines. World Development, 98, 214-230. https://doi.org/10.1016/j. worlddev.2017.04.028

Collins, A. C., Coughlin, D., Miller, J., \& Kirk, S. (2015). The production of quick scoping reviews and rapid evidence assessments: A how to guide. United Kingdom Department for Environment Food and Rural Affairs and Natural Environment Research Council. https:// assets.publishing.service.gov.uk/government/ uploads/system/uploads/attachment_data/file/560521/ Production_of_quick_scoping_reviews_and_rapid_ evidence_assessments.pdf

de Sousa, K., Casanoves, F., Sellare, J., Ospina, A., Suchini, J. G., Aguilar, A., \& Mercado, L. (2018). How climate awareness influences farmers' adaptation decisions in Central America? Journal of Rural Studies, 64, 11-19. https://doi.org/10.1016/j. jrurstud.2018.09.018

Derbile, E., Jarawura, F., \& Dombo, M. (2016). Climate change, local knowledge and climate change adaptation in Ghana. In J. H. Joseph \& A. Yaro (Eds.), Adaptation to climate change and variability in rural West Africa. Springer. 
Donatti, C., Harvey, C. A., Martinez-Rodriguez, M. R., Vignola, R., \& Rodriguez, C. M. (2019). Vulnerability of smallholder farmers to climate change in Central America and Mexico: Current knowledge and research gaps. Climate and Development, 11(3), 264-286. https://doi.org/10.1080/17565529.2018.1442796

El Chami, D., Daccache, A., \& Moujabber, M. E. (2020). How can sustainable agriculture increase climate resilience? A systematic review. Sustainability, 12(8), 3119. https://doi.org/10.3390/su12083119

Etana, D., Snelder, D. J., van Wesenbeeck, C. F., \& de Cock Buning, T. (2020). Dynamics of smallholder farmers' livelihood adaptation decision-making in Central Ethiopia. Sustainability, 12(11), 4526. https:// doi.org/10.3390/su12114526

Food and Agriculture Organization of the United Nations. (2014). Adapting to climate change through land and water management in Eastern Africa: Results of pilot projects in Ethiopia, Kenya and Tanzania. http://www. fao.org/family-farming/detail/en/c/853718/

Guido, Z., Finan, T., Rhiney, K., Madajewicz, M., Rountree, V., Johnson, E., \& McCook, G. (2018). The stresses and dynamics of smallholder coffee systems in Jamaica's Blue Mountains: A case for the potential role of climate services. Climatic Change, 147(1-2), 253-266. https://doi.org/10.1007/s10584-017-2125-7

Gusenbauer, D., \& Franks, P. (2019). Agriculture, nature conservation or both? Managing trade-offs and synergies in sub-Saharan Africa. International Institute for Environment and Development. https://pubs.iied. org/14675IIED

Hameso, S. (2017). Farmers and policy-makers' perceptions of climate change in Ethiopia. Climate and Development, 10(4), 347-359. https://doi.org/10.1080 $/ 17565529.2017 .1291408$

Henriksson, R., Vincent, K., Archer, E., \& Jewitt, G. (2020). Understanding gender differences in availability, accessibility and use of climate information among smallholder farmers in Malawi. Climate and Development. https://doi.org/10.1080/17565529.2020 .1806777

Hulke, C., \& Revilla Diez, J. (2020). Building adaptive capacity to external risks through collective action Social learning mechanisms of smallholders in rural Vietnam. International Journal of Disaster Risk Reduction, 51, 101829. https://doi.org/10.1016/j. ijdrr.2020.101829

International Fund for Agricultural Development. (2020) Adaptation for smallholder agriculture programme: ASAP. https://www.ifad.org/ documents/38714170/40213192/asap.pdf/ b5a8c1f9-f908-4a68-ad30-e3d5eeb17c31

Kerr, R. B., Nyantakyi-Frimpong, H., Dakishoni, L., Lupafya, E., Shumba, L., Luginaah, I., \& Snapp, S. S. (2018). Knowledge politics in participatory climate change adaptation research on agroecology in Malawi. Renewable Agriculture and Food Systems, 33(3), 238 251. https://doi.org/10.1017/S1742170518000017
Khan, M. A., \& Akhtar, M. S. (2015). Agricultural adaptation and climate change policy for crop production in Africa. In K. R. Hakeem (Ed.), Crop production and global environmental issues (pp. 437-541). Springer International.

Khanal, U., Wilson, C., Hoang, V., \& Lee, B. (2019). Impact of community-based organizations on climate change adaptation in agriculture: Empirical evidence from Nepal. Environment Development and Sustainability, 21(2), 621-635. https://doi. org/10.1007/s10668-017-0050-6

Lasco, R. D., Delfino, R. J., \& Espaldon, M. L. (2014). Agroforestry systems: Helping smallholders adapt to climate risks while mitigating climate change. Wiley Interdisciplinary Reviews: Climate Change, 5, 825833. https://doi.org/10.1002/wcc.301

Lemos, M., Agrawal, A., Eakin, H., Nelson, D., \& Engle. (2013). Building adaptive capacity to climate. In A. Ghassem \& J. W. Hurrell (Eds.), Climate science for serving society: Research, modelling and prediction priorities. Springer.

Levin, K., Cashore, B., \& Bernstein, S. (2012). Overcoming the tragedy of super wicked problems: Constraining our future selves to ameliorate global climate change. Policy Sciences, 45, 123-152. https:// doi.org/10.1007/s11077-012-9151-0

López, S., López-Sandoval, M., \& Jung, J.-K. (2020). New insights on land use, land cover, and climate change in human-environment dynamics of the Equatorial Andes. Annals of the American Association of Geographers. https://doi.org/10.1080/24694452.20 20.1804822

Lowder, S. K., Skoet, J., \& Raney, T. (2016). The number, size and distribution of farms, smallholder farms and family farms worldwide. World Development, 87, 16-29. https://doi.org/10.1016/j. worlddev.2015.10.041

Makate, C. (2019). Local institutions and indigenous knowledge in adoption and scaling of climate-smart agricultural innovations among sub-Saharan smallholder farmers. International Journal of Climate Change Strategies and Management, 12(2), 270-287. https://doi.org/10.1108/IJCCSM-07-2018-0055

Mapfumo, P., Adjei-Nsiah, S., Mtambanengwe, F., Chikowo, R., \& Giller, K. E. (2013). Participatory action research (PAR) as an entry point for supporting climate change adaptation by smallholder farmers in Africa. Environmental Development, 5, 6-22. https:// doi.org/10.1016/j.envdev.2012.11.001

Marquardt, K., Pain, A., \& Khatri, D. B. (2020). Re-reading Nepalese landscapes: Labour, water, farming patches and trees. Forests, Trees and Livelihoods, 29(4), 238-259. https://doi.org/10.1080/14728028.20 20.1814875

Neufeldt, H., Negra, C., Hancock, J., \& Foster, K. (2015). Scaling up climate-smart agriculture: Lessons learned from South Asia and pathways for success. World Agroforestry Centre. https://doi.org/10.5716/ WP15720.PDF\%20 
Newsham, A., \& Thomas, D. (2009). Agricultural adaptation, local knowledge and livelihoods diversification in North-Central Namibia. Tyndall Centre for Climate Change.

Nigussie, Y., van der Werf, E., Zhu, X., Simane, B., \& van Ierland, E. C. (2018). Evaluation of climate change adaptation alternatives for smallholder farmers in the Upper Blue-Nile Basin. Ecological Economics, 151, 142-150. https://doi.org/10.1016/j. ecolecon.2018.05.006

Nyantakyi-Frimpong, H., Matouš, P., \& Isaac, M. E. (2019). Smallholder farmers' social networks and resource-conserving agriculture in Ghana: A multicase comparison using exponential random graph models. Ecology and Society, 24(1), 5. https://doi.org/10.5751/ ES-10623-240105

Partey, S. T., Zougmoré, R. B., Ouédraogo, M., \& Campbell, B. M. (2018). Developing climate-smart agriculture to face climate variability in West Africa: Challenges and lessons learnt. Journal of Cleaner Production, 187, 285-295. https://doi.org/10.1016/j. jclepro.2018.03.199

Popoola, O. O., Yusuf, S. F., \& Monde, N. (2020). Information sources and constraints to climate change adaptation amongst smallholder farmers in Amathole District Municipality, Eastern Cape Province, South Africa. Sustainability, 12(14), 5846. https://doi. org/10.3390/su12145846

Pullin, A. S., Frampton, G. K., Livoreil, B., \& Petrokofsky, G. (Eds.). (2018). Guidelines and standards for evidence synthesis in environmental management, version 5.0. Collaboration for Environmental Evidence https:// environmentalevidence.org/information-for-authors/

Quandt, A. (2020). Contribution of agroforestry trees for climate change adaptation: Narratives from smallholder farmers in Isiolo, Kenya. Agroforestry Systems, 94(6), 2125-2136. https://doi.org/10.1016/j. gloenvcha.2006.02.006

Reid, H. (2016). Ecosystem- and community-based adaptation: Learning from community-based natural resource management. Climate and Development, 8(1), 4-9. https://doi.org/10.1080/17565529.2015.10 34233

Reid, H., Chambwera, M., \& Murray, L. (2013). Tried and tested: Learning from farmers on adaptation to climate change. International Institute for Environment and Development. https://pubs.iied.org/14622IIED

Roncoli, C., Okoba, B., \& Gathaara, V. (2010). Adaptation to climate change for smallholder agriculture in Kenya: Community-based perspectives from five districts (Project note from adaptation of smallholder agriculture to climate change in Kenya project). International Food Policy Research Institute.

Ruijs, A., de Bel, M., Kononen, M., Linderhof, V., \& Polman, N. (2011). Adapting to climate variability: Learning from past experience and the role of institutions. World Bank. https://openknowledge.worldbank. org/handle/10986/26896
SaintVille, A. S., Hickey, G. M., Locher, U., \& Phillip, L. E. (2016). Exploring the role of social capital in influencing knowledge flows and innovation in smallholder farming communities in the Caribbean. Food Security, 8(3), 535-549. https://doi.org/10.1007/ s12571-016-0581-y

Shackleton, S., Ziervogel, G., Sallu, S., Gill, T., \& Tschakert, P. (2015). Why is socially-just climate change adaptation in sub-Saharan Africa so challenging? A review of barriers identified from empirical cases. Wiley Interdisciplinary Reviews: Climate Change, 6(3), 321-344. https://doi.org/10.1002/ wcc. 335

Shah, S. I., Zhou, J., \& Shah, A. A. (2019). Ecosystembased adaptation practices in smallholder agriculture: Emerging evidence from rural Pakistan. Journal of Cleaner Production, 218, 673-684. https://doi. org/10.1016/j.jclepro.2019.02.028

Shaw, A., \& Kristjanson, P. (2014). A catalyst toward sustainability? Exploring social learning and social differentiation approaches with the agricultural poor. Sustainability, 6(5), 2685-2717. https://doi. org/10.3390/su6052685

Silici, L., Rowe, A., Suppiramaniam, N., \& Knox, J. W. (in press). Building adaptive capacity of smallholders to climate change: Review and synthesis of evidence on learning outcomes. Environmental Research Letters.

Sova, C., Vervoort, J., Thornton, T., Helfgott, A., Matthews, D., \& Chaudhury, A. (2015). Exploring farmer preference shaping in international agricultural climate change adaptation regimes. Environmental Science \& Policy, 54, 463-474. https://doi.org/10.1016/j. envsci.2015.08.008

Stringer, L., Fraser, E. D. G., Harris, D., Lyon, C., Pereira, L., Ward, C. F. M., \& Simelton, E. (2020). Adaptation and development pathways for different types of farmers. Environmental Science and Policy, 104, 174-189. https://doi.org/10.1016/j.envsci.2019.10.007

Taylor, M. (2018). Climate-smart agriculture: What is it good for? The Journal of Peasant Studies, 45(1), 89-107. https://doi.org/10.1080/03066150.2017.131 2355

United Nations Environment Programme. (2018). The adaptation gap report 2018. https://www.unep.org/ resources/adaptation-gap-report-2018

Vermeulen, S., Mason, M., Dinesh, D., \& Adolph, B. (2015). Radical adaptation in agriculture: Tackling the roots of climate vulnerability. International Institute for Environment and Development. https:// pubs.iied.org/17309IIED

Vermeulen, S. J., Dhanush, D., Howden S., M., Cramer, L., \& Thornton, P. K. (2018). Transformation in practice: A review of empirical cases of transformational adaptation in agriculture under climate change. Frontiers in Sustainable Food Systems, 2, 65. https:// doi.org/10.3389/fsufs.2018.00065 
Vignola, R., Harvey, C. A., Bautista-Solis, P., Avelino, J., Rapidel, B., \& Camila Donatti, R. M. (2015). Ecosystem-based adaptation for smallholder farmers: Definitions, opportunities and constraints. Agriculture, Ecosystems \& Environment, 211, 126-132. https://doi. org/10.1016/j.agee.2015.05.013

Wekesa, C., Ongugo, P., Ndalilo, L., Amur, A., Mwalewa, S., \& Swiderska, K. (2017). Smallholder farming systems in coastal Kenya: Key trends and innovations for resilience. International Institute for Environment and Development. https://pubs.iied.org/17611IIED
Wise, R. M., Fazey, I., Stafford Smith, M., Park, S. E., Eakin, H. C., Archer Van Garderen, E. R. M., \& Campbell, B. (2014). Reconceptualising adaptation to climate change as part of pathways of change and response. Global Environmental Change, 28, 325336. https://doi.org/10.1016/j.gloenvcha.2013.12.002

Wright, H., Vermeulen, S., Laganda, G., Olupot, M., Ampaire, E., \& Jat, M. L. (2014). Farmers, food and climate change: Ensuring community-based adaptation is mainstreamed into agricultural programmes. Climate and Development, 6(4), 318-328. https://doi. org/10.1080/17565529.2014.965654

Open Access This chapter is licensed under the terms of the Creative Commons Attribution 4.0 International License (http://creativecommons.org/licenses/by/4.0/), which permits use, sharing, adaptation, distribution and reproduction in any medium or format, as long as you give appropriate credit to the original author(s) and the source, provide a link to the Creative Commons license and indicate if changes were made.

The images or other third party material in this chapter are included in the chapter's Creative Commons license, unless indicated otherwise in a credit line to the material. If material is not included in the chapter's Creative Commons license and your intended use is not permitted by statutory regulation or exceeds the permitted use, you will need to obtain permission directly from the copyright holder. 